\title{
RESPONSE OF CITRIC ACID LEVELS TO ORAL ADMINISTRATION \\ OF GLUCOSE. II. ABNORMALITIES OBSERVED IN THE DIABETIC AND CONVULSIVE STATE ${ }^{1}$
}

\author{
By JOSEPH B. PINCUS, SAMUEL NATELSON, AND JULIUS K. LUGOVOY \\ (From the Department of Biochemistry and the Pediatric Research Laboratories, \\ Jewish Hospital of Brooklyn, Brooklyn, N. Y.)
}

(Received for publication January 12, 1948)

In the first paper of this series (1) it was demonstrated in vivo in humans that the normal response to active carbohydrate metabolism, as in the postabsorptive period for glucose, or after injection of insulin, is a lowering of blood citric acid levels.

In the studies presented below, the nature of the citric acid response curve in abnormal conditions is explored with the hope of throwing more light on the nature of the mechanism linking citric acid metabolism with glucose removal from the blood stream.

When abnormalities occurred they were apparent during the first three hours of this test. For this reason and for the convenience of the patient, we discarded the six-hour test and substituted a three-hour test, seeking the contour of the first half of the citric acid curve.

1 Presented in part at the Meeting of the American Chemical Society, New York City, Sept. 15, 1947.
In order to see the effect of a disturbed insulin balance on citric acid levels we applied this study to diabetic adults. A large majority of diabetics exhibited a citric acid response which was not markedly different from that of the normal. A few typical examples are illustrated in Figure 1.

In some diabetics, however, the diabetic state was complicated by an abnormal citric acid response. This abnormality took the form of a rapidly rising level of citric acid which did not fall during the test period.

Another form of abnormality observed, was a sharp rise for the first hour followed by a lowering of the citric acid level to a minimum. These abnormal results were observed in cases of diabetes which were difficult to control with insulin therapy. These patients also had neurological symptoms, abnormal electro-encephalograms, and tended to go into insulin shock readily. The following curves obtained illustrate this type of response (Figure 2).

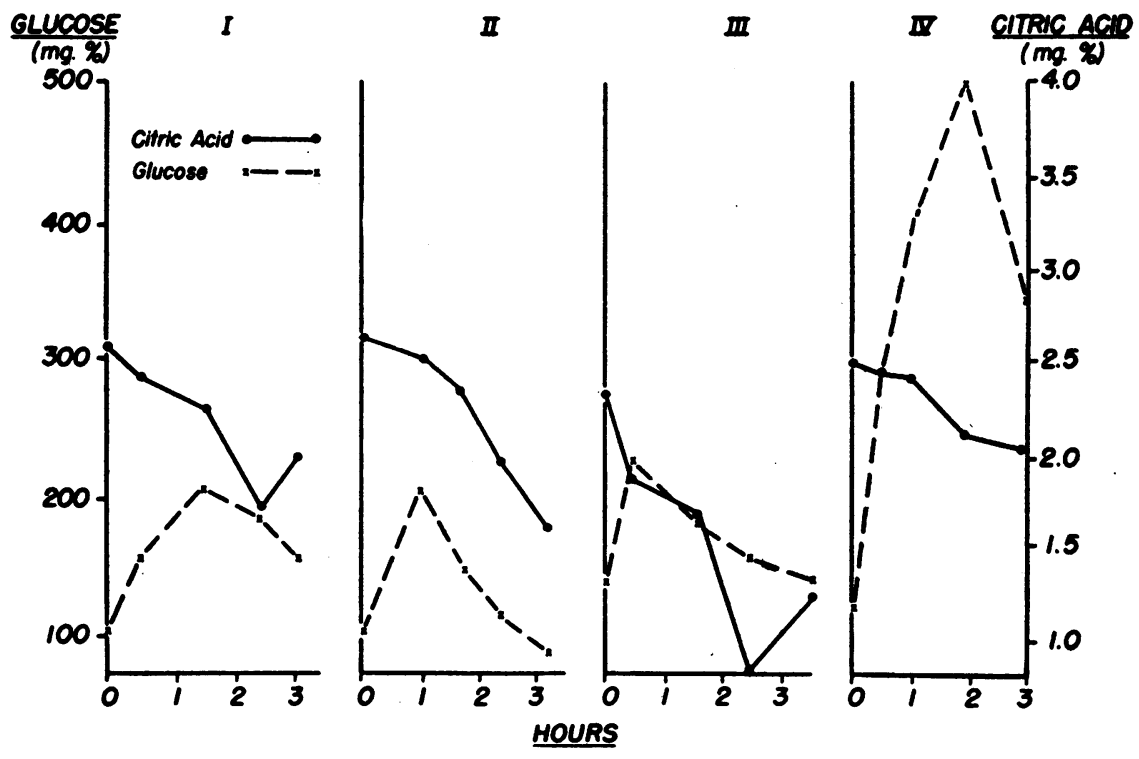

Fig. 1. Diabetics with Citric Acid Level Response Resembling the Normal. 
CITRIC ACID LEVEL RESPONSE TO GLUCOSE GIVEN ORALLY. II

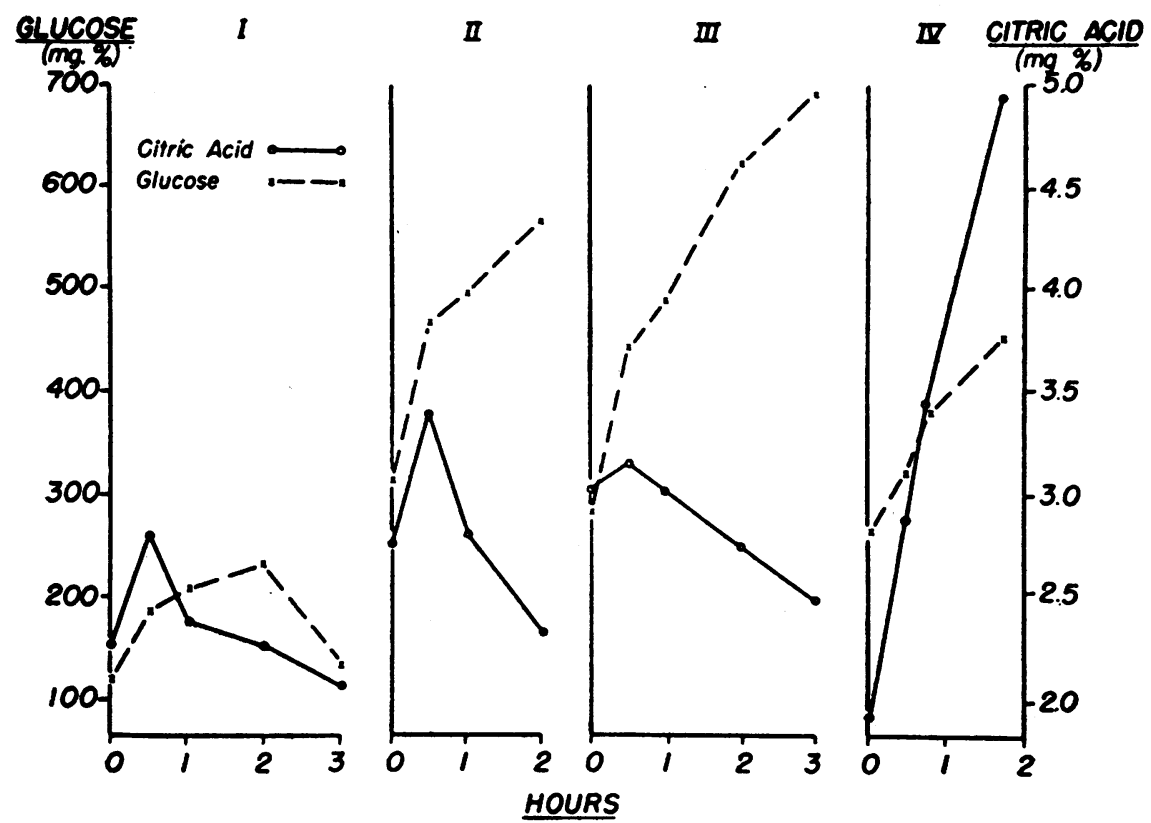

Fig. 2. Diabetics with Abnormal Citric Acid Response

The rise of citric acid levels in certain pathological conditions raised the problem as to whether citric acid concentration would ever rise to a level where it would seriously affect the calcium ion concentration and, therefore, interfere with the normal action of calcium ion on muscle (2) and the oxidative system (3-7). It was therefore decided to study the citric acid response in children with symptoms of convulsions. Among the children studied in this group, six were encountered whose glucose tolerance curves were non-diabetic, but whose citric acid response was abnormal. This took the form of:
(1) a continuous rise in citric acid levels during the test (Figure 3, Case I)

(2) a rise followed by a delayed return to the fasting level (Figure 3, Cases II and IV)

(3) a rise above the fasting level, followed by a lowering to a minimum below the fasting level (Figure 3, Case III).

The curves for four of these convulsives are shown in Figure 3.

One newborn child with typical symptoms of tetany (i.e., carpopedal spasm, etc.), but with a total calcium not much below the normal range, was studied.
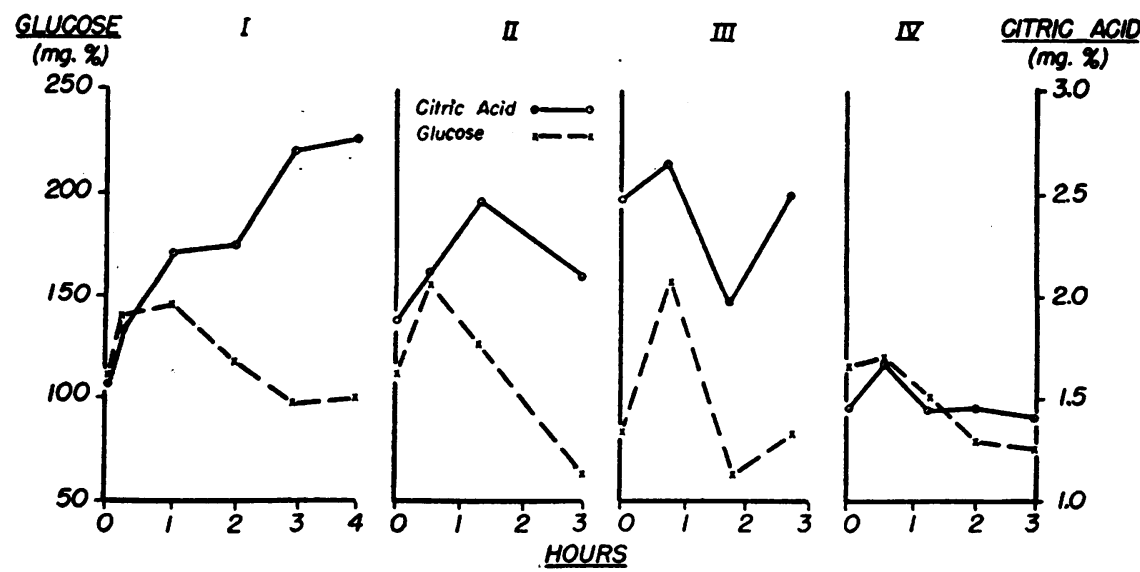

Fig. 3. Convulsives with Abnormal Citric Acid Response 
This child had a total blood calcium level of 8 mg. \%, but a citric acid level of $9.7 \mathrm{mg}$. \%. This would approximate an increase in citric acid of from about three to five times over the normal range. The calcium level of $8 \mathrm{mg}$. \% could not explain the tetany. Calculations showed that if such a rise of citric acid concentration were to occur in the spinal fluid the increase in citrate level would cause a drop in calcium ion of $39 \%$, which should be of physiological significance. These calculations were done for spinal fluid for it has been demonstrated that the calcium ion concentration in spinal fluid is controlled by the concentration of citrate alone, the protein effect being slight (8). Citric acid levels in spinal fluid are higher than that in the serum (9).

\section{DISCUSSION}

Figures 1 and 2 indicate that diabetics may be classified in accordance with their citric acid level response to administration of glucose.

It should be noted that the severity of the diabetic curve is no index of the citric acid response. In the diagrams above, Figure 2, Case I has a mild form of diabetes but an abnormal citric acid response. Case II exhibits a more severe form of diabetes and a response similar to Case I. Case III with severe diabetes exhibits a mild deviation from the normal. Case IV has a most abnormal citric acid response although her form of diabetes seems to be less severe than Case II or III. Case IV during her stay in the hospital was in shock or coma most of the time, and was admitted for a possible brain tumor, for which there were found to be negative clinical findings. This would indicate that the lowering of citric acid levels in the human on administration of glucose is not proportionately related to the patient's insulin response. Of pertinent interest is the observation of Stoppani that administration of glucose alone to depancreatinized dogs causes a rise in citric acid levels (10).

It is probable that in severe diabetes a substantial portion of the citric acid in the serum rises from fat metabolism via acetoacetic acid with the aid of citrogenase in the presence of oxalacetic acid from the oxidative cycle (11-13). This mechanism would make it possible for citric acid levels to build up even though the formation of substantial amounts of pyruvic acid were blocked by lack of insulin.

The curves for those convulsive children (Figure 3), where the glucose tolerance curves seemed to be essentially normal but the citric acid levels tended to rise during the tests, are of interest. These observations and the observations on diabetics with abnormal insulin-citric acid response may be interpreted as signifying that normal insulin equilibrium or abnormal insulin equilibrium is no indicator of the ability of the body to metabolize citric acid. Certain convulsive children exhibit evidence of abnormality in citric acid metabolism only. Abnormality in citric acid metabolism may, therefore, be interpreted as due to an abnormality in the function of the oxidative cycle.

The reasoning for this conclusion is based on experiments in vitro and in vivo with malonic acid, a specific inhibitor for the succinoxidase system. Addition of malonic acid to tissue in vitro will cause a rise in citric acid $(14,15)$. Injection of malonic acid into normal dogs causes a rise in citric acid serum levels (10). Thus, the condition in these patients with abnormal citric acid response might be compared to that in the animals with an inhibited oxidative cycle.

In the light of our studies it is suggested that a more intimate study of the oxidative cycle of patients with convulsive seizures of unknown origin and of diabetics with abnormal response to insulin therapy should be a fruitful method of attack on these problems.

Citric acid level response to oral administration of glucose may serve as an indicator in detecting in vivo changes of a portion of this system.

It has been demonstrated that the diffusible calcium changes in convulsions in children (16). That citric acid forms an un-ionized calcium complex is based on sound experimental evidence. Shelling and Maslow (17) demonstrated that in convulsions induced by administration of sodium citrate in massive doses, the diffusible calcium rose to a high level. They drew the conclusion that calcium forms a poorly ionized complex with citric acid. A number of years later Shear and Kramer (18) demonstrated by conductivity measurements that such was the case. In 1934 Hastings et al. $(7,19)$ studied this problem quantitatively. They drew the conclusion that calcium formed a poorly 
dissociated complex with citric acid in the blood and spinal fluid. Similar observations were made with magnesium ions.

From the findings on the infant in tetany, one would expect that some cases of tetany may be explained by abnormally high citric acid levels. However, it must be stressed that this is probably not the case in the convulsive seizure as usually observed in convulsives. In these cases an impaired or inhibited oxidative system should be investigated as a possible cause.

\section{SUM MARY}

1. A study of citric acid levels in response to glucose administration was made in humans where abnormal glucose metabolism was suspected.

2. Most diabetics show no apparent deviation from the normal citric acid level response curve on administration of glucose orally.

3. Certain diabetics, with neurological symptoms, show abnormalities in their citric acid response to the administration of glucose.

4. Some children with symptoms of convulsive seizures show abnormal citric acid response curves, but non-diabetic glucose tolerance curves.

5. Citric acid levels can rise in pathological conditions to levels where calcium ion concentration can be significantly affected.

\section{BIBLIOGRAPHY}

1. Natelson, S., Pincus, J. B., and Lugovoy, J. K., Response of citric acid to oral administration of glucose. I. Normal adults and children. J. Clin. Invest., 1948, 27, 446.

2. Szent-Györgi, Muscular contraction. Acta. Physiol. Scandinav., Suppl. 25, 1945, 9, 1-115.

3. Peters, R. A., and Wakelin, R. W., The dissociating power of salts of fatty acids. Biochem. J., 1938, 32, 2290.

4. Axelrod, A. E., Swingle, K. F., and Elvehjem, C. A., Stimulatory effect of calcium on the succinoxidase activity of fresh rat tissue. J. Biol. Chem., 1941, 140, 931.

5. Potter, V. R., and Schneider, W. C., Studies on mechanism of hydrogen transport in animal tissues. V. Dilution effects in the succinoxidase system. J. Biol. Chem., 1942, 142, 543.

6. Swingle, K. F., Axelrod, A. E., and Elvehjem, C. A., Mechanism of effect of calcium salts on the succinoxidase system. J. Biol. Chem., 1942, 145, 581.

7. Ames, S. R., Effect of calcium on the inhibition of the succinic oxidase system by $d$ - $\alpha$-tocopherol phosphate. J. Biol. Chem., 1947, 169, 503.

8. McLean, F. C., and Hastings, A. B., The state of calcium in the fluids in the body. I. The condition affecting the ionization of calcium. J. Biol. Chem., 1935, 108, 285.

9. Benni, B., The citric acid content of cerebrospinal fluid. Biochem. Ztschr., 1930, 221, 270.

10. Stoppani, A. O. M., Diabetes and citric acid metabolism. Medicina, 1946, 6, 389.

11. Hunter, F. E., and Leloir, L. F., Citric acid formation from acetoacetic and oxalacetic acids. J. Biol. Chem., 1945, 159, 295.

12. Buchanan, J. M., Sakami, W., Gurin, S., and Wilson, D. W., A study of the intermediates of acetate and acetoacetate oxidation with isotopic carbon. J. Biol. Chem., 1945, 159, 695.

13. Breusch, F. L., Breakdown of fat acids in tissue. I. The breakdown of keto acids. Enzymologia, 1944, 11, 169.

14. Krebs, H. A., Salvin, E., and Johnson, W. A., Formation of citric and $\alpha$-ketoglutaric acids in the mammalian body. Biochem. J., 1938, 32, 113.

15. Munoz, J. M., and Stoppani, A. O. M., Composition of the enzyme system oxidising citric acid. Rev. Soc. argent. de biol., 1944, 20, 594.

16. Pincus, J. B., Peterson, H. A., and Kramer, B., Study by means of ultrafiltration of the condition of several inorganic constituents of blood serum in disease. J. Biol. Chem., 1926, 68, 601.

17. Shelling, D. H., and Maslow, H. L., Effect of sodium citrate acetate and lactate on the ultrafiltrability of serum calcium. J. Biol. Chem., 1928, 78, 661.

18. Shear, M. J., and Kramer, B., Composition of bone. V. Some properties of calcium citrate. J. Biol. Chem., 1928, 79, 161.

19. McLean, F. C., and Hastings, A. B., Biological method for the estimation of calcium ion concentration. J. Biol. Chem., 1934, 107, 337. 